\title{
Análise compreensiva do significado do atendimento ao adolescente realizado pelos profissionais de saúde da atenção primária do Município de Viçosa, MG
}

\author{
Comprehensive analysis of the meaning to care the adolescent performed by occupation health attention in \\ primary care of the municipality of the Viçosa, Minas Gerais State, Brazil \\ Análisis comprensivo del significado del atendimiento al adolescente realizado por los profesionales de salud de la \\ atención primaria en el Municipio de Viçosa, Minas Gerais, Brasil
}

O presente trabalho é um estudo de natureza qualitativa, com abordagem fenomenológica, que teve como objetivo compreender o significado do atendimento a adolescentes realizado pelos profissionais da atenção básica do município de Viçosa-MG. A pesquisa foi realizada com profissionais de nível superior, médicos e enfermeiros, que trabalhavam nas Equipes da Estratégia Saúde da Família. Os dados foram colhidos nos meses de fevereiro e março de 2009, por meio de uma entrevista individual com os profissionais que aceitaram participar da pesquisa. A entrevista foi aberta, guiada por uma questão norteadora: "O que é, para você, atender o adolescente na atenção primária?". Por meio do critério de repetição das falas chegou-se a 12 entrevistados, cujos discursos foram avaliados segundo a análise ideográfica proposta por Martins e Bicudo (1989), o que possibilitou construir 12 unidades temáticas. Estas unidades confluíram para três grandes categorias de análise, que elucidam o atendimento ao adolescente: "Atendimento ao adolescente: os desafios da atenção primária", "Atendimento ao adolescente na atenção primária: características da prática assistencial", "Atender o adolescente: uma necessidade da atenção primária". Para os profissionais que participaram da pesquisa o atendimento ao adolescente ainda é um grande desafio, com muitos obstáculos. Nesse contexto destacam-se questões relacionadas à dificuldade em lidar com essa população, à falta de capacitação, à sobrecarga de trabalho, dentre outros elementos. Outros pontos evidenciados estão relacionados ao atendimento realizado pelos profissionais nas equipes, muitas vezes direcionados para as características, os riscos e os agravos da adolescência. Os participantes colocam, também, que é necessário atender o adolescente, e que o serviço de saúde deve se organizar para esta finalidade. $\mathrm{O}$ desocultamento do fenômeno indica que existem questões importantes para serem discutidas e melhoradas com relação ao atendimento ao adolescente na atenção primária. Neste contexto vários atores devem ser envolvidos, dentre eles o profissional e o adolescente, que são as peças fundamentais dessa organização.

Bruno David Henriques Dissertação de Mestrado (2009) Programa de Pós-Graduação em Ciências da Saúde: Saúde da Criança e do Adolescente, Faculdade de Medicina, Universidade Federal de Minas Gerais. brunoenfer@yahoo.com.br

Palavras-chave: Atenção primária. Saúde do adolescente. Pesquisa qualitativa. Fenomenologia.

Keywords: Primary care. Health of adolescents. Qualitative research. Phenomenology.

Palabras clave: Atención primaria. Salud del adolescente. Investigación cualitativa. Fenomenología.

Texto na íntegra disponível em: http://www.bibliotecadigital.ufmg.br/dspace/handle/1843/ ECJS-7W8P86 